\title{
Enneking High Surgical Grade
}

National Cancer Institute

\section{Source}

National Cancer Institute. Enneking High Surgical Grade. NCI Thesaurus. Code C140261.

A high-grade lesion, corresponding to Broder's Grades 3 and 4, having a higher incidence of metastasis and characterized histologically by mitotic figures, prominent nucleoli, and pleomorphism. 